\title{
Primary Care Patients Hastening Death by Voluntarily Stopping Eating and Drinking
}

\author{
Eva E. Bolt, $M D^{1}$ \\ Martijn Hagens, MSc ${ }^{1}$ \\ Dick Willems, $M D, P b D^{2}$ \\ Bregje D. Onwuteaka-Pbilipsen, \\ $\mathrm{PbD}{ }^{1}$ \\ 'Department of Public and Occupational \\ Health, EMGO Institute for Health and \\ Care Research, VUmc Expertise Center \\ for Palliative Care, VU University Medical \\ Center, Amsterdam, The Netherlands \\ ${ }^{2}$ Department of General Practice, Section \\ of Medical Ethics, Academic Medical Cen- \\ ter, University of Amsterdam, Amsterdam, \\ The Netherlands
}

\begin{abstract}
PURPOSE Little is known about the role family physicians play when a patient deliberately hastens death by voluntarily stopping eating and drinking (VSED). The purpose of this study was to gain more insight for family physicians when confronted with patients who wish to hasten death by VSED. We aimed to describe physicians' involvement in VSED, to describe characteristics and motives of their patients, and to describe the process of VSED in terms of duration, as well as common symptoms in the last 3 days of life.
\end{abstract}

METHODS We undertook a survey of a random national sample of 1,100 family physicians (response rate 72\%), and 500 of these physicians received questions about their last patient who hastened death by VSED.

RESULTS Of the 978 eligible physicians, 708 responded $(72.4 \%) ; 46 \%$ had cared for a patient who hastened death by VSED. Of the 500 physicians who received the additional questions, 440 were eligible and 285 (64.8\%) responded; they described 99 cases of VSED. Seventy percent of these patients were aged older than 80 years, $76 \%$ had severe disease (27\% with cancer), and $77 \%$ were dependent on others for everyday care. Frequent reasons for the patients' death wish were somatic (79\%), existential (77\%), and dependence (58\%). Median time until death was 7 days, and the most common symptoms before death were pain, fatigue, impaired cognitive functioning, and thirst or dry throat. Family physicians were involved in $62 \%$ of cases.

CONCLUSIONS Patients who hasten death by VSED are mostly in poor health. It is not unlikely for family physicians to be confronted with VSED. They can play an important role in caring for these patients and their proxies by informing them of VSED and by providing support and symptom management during VSED.

Ann Fam Med 2015;13:421-428. doi: 10.1370/afm.1814.

\section{INTRODUCTION}

$\mathrm{P}$ atient autonomy and control are important themes at the end of life, $^{1-3}$ and losing control and dependence are leading factors associated with a desire to hasten death. ${ }^{4,5}$ Moreover, having control over the dying process is identified as a key attribute of a good death in Western society. ${ }^{1,2,6,7}$ For people who suffer unbearably and wish to hasten death, voluntary stopping of eating and drinking (VSED) $)^{8-11}$ is described as a feasible method for them to control the timing and circumstances of their death. Ivanović et al defined VSED as "an action of a competent, capacitated person, who voluntarily and deliberately chooses to stop eating and drinking with the primary intention to hasten death because unacceptable suffering persists."12 In contrast to physician-assisted suicide (PAS), approval and support of a physician is not necessary in VSED, expanding patient autonomy. ${ }^{13,14}$ Nevertheless, in practice patients who opt for VSED often require medical support. ${ }^{15,16}$

Physicians and nurses confronted with VSED may feel moral unease and can be reluctant to support the patient in a path leading to death. ${ }^{15,17,18}$ Most experts agree, however, that patients are free to refuse food and fluid, much as they are free to refuse medical treatment. A physician who 
is convinced that the decision is well-considered is morally obliged to honor it. ${ }^{8,9}, 15$ Physicians may even have a duty to become involved as caregivers, because every person has the right to relief of distress. ${ }^{8,15,19}$ Involvement may consist of counseling and giving information about VSED, as well as symptom management and support during VSED. ${ }^{9,19,20}$ Whether palliative sedation in case of refractory symptoms is acceptable is a subject of debate. ${ }^{16}$

In 1993, Bernat et al described the need for systematic research on the process of VSED to help physicians understand patients' needs. ${ }^{9}$ Two decades later this call has hardly been answered, even though VSED occurs quite frequently $(0.4 \%$ to $2.1 \%$ of deaths in the Netherlands). ${ }^{12,21,22}$ Although much has been written on VSED, the literature mostly comprises commentaries and case reports rather than original research. ${ }^{3,9,10,12,15,20}$ Most authors draw a positive picture of VSED, but they also describe the need for palliative care. ${ }^{9,11,15,23}$ They mention possible serious complications, such as a prolonged dying phase, thirst or hunger, agitation, delirium, and overburdened family members. ${ }^{10,11,14,17,24}$ There are no data, however, on the prevalence of symptoms for which palliative care is indicated. ${ }^{12}$ The only studies reporting data on multiple patients choosing death by VSED have been results of surveys by Chabot $^{11}$ and Ganzini et al. ${ }^{23}$ They have reported a comfortable death within 15 days for most patients, but they did not describe complications or physician involvement. Duration until death may be associated with the patient's health condition. ${ }^{22}$

Patients who elect to die by VSED may be at risk of not receiving appropriate palliative care. Because of the autonomous nature of VSED, patients might not involve their physicians, ${ }^{11}$ physicians might be reluctant to become involved, ${ }^{10,18}$ and physicians might lack knowledge of how to care for these patients. ${ }^{12}$ Concerns about the risk of patients not receiving appropriate care prompted us to undertake this exploratory study to gain insight into current practices.

First, we wanted to describe VSED. Such information can be used by family physicians to counsel and inform patients and proxies, and to help physicians understand patients' needs during VSED. We further wanted to understand which patients hasten death by VSED and their motives, as well as what happens during VSED in terms of symptoms and duration of the dying process and what factors are associated with time until death.

Second, we aimed to describe the involvement of family physicians in VSED. We were interested to find out how many family physicians have experienced VSED, what role they play in VSED, and whether family physicians find it conceivable to administer palliative sedation in VSED.

\section{METHODS Design and Population}

This study was conducted among family physicians because they can report on cases in home settings, residential homes, and hospices. We expected family physicians to experience VSED infrequently, so we used a retrospective approach. We mailed a questionnaire to a random nationwide sample of 1,100 family physicians; of these physicians, we mailed 500 a more detailed questionnaire. Addresses were obtained from a national databank. ${ }^{25}$ Inclusion criteria were working as family physician in the Netherlands in the last year, and having a registered work address. According to Dutch law, the study did not require review by an ethics committee because participants were not subjected to procedures or required to follow rules of behavior. ${ }^{26}$

\section{Data Collection}

The questionnaire was pilot tested with 12 physicians. Data collection took place from October 2011 to June 2012, and 2 reminders were sent to nonresponders. The questionnaires were unnumbered and anonymous. In the questionnaire, VSED was defined as "deliberately stopping eating and drinking with the explicit intention to die (not in the context of anorexia or cachexia due to terminal disease)." All physicians were asked whether a patient had ever died as a consequence of VSED. They were further asked whether it was conceivable that they would apply (or had ever applied) palliative sedation for such a patient, and whether they had ever suggested the possibility of VSED to a patient with a wish for PAS. Finally, the questionnaire included questions on age, sex, religion, work experience, additional expertise on palliative care, and experience with (and attitude toward) PAS.

We collected data on individual VSED cases from a subsample of 500 of the initial respondents. These 500 family physicians received additional questions about the last case of VSED in which they were the primary treating physician. This questionnaire included multiple-choice questions about their patients' characteristics: age, marital status, place of residence, Eastern Cooperative Oncology Group (ECOG) performance status ${ }^{27}$ life expectancy (before VSED), diagnosis (cancer, another physical disease, psychiatric disease, early-stage dementia, or no severe physical/psychiatric disease), and level of mental competence (competent, somewhat competent, incompetent, don't know).

Questions regarding patients' decisions to elect VSED related to motives for wanting to die (derived from studies on euthanasia requests), ${ }^{28,29}$ whether the family physicians suggested the possibility of VSED, whether the patients had previously requested PAS, and whether the family physicians agreed with the patients' 
decision (yes/mostly or no/barely). The physicians were asked about involvement of others, whether the family physicians were informed in advance, and whether they and/or proxies were involved before or during VSED (including palliative sedation). During the implementation phase, physicians were asked how many days passed between when the patients stopped eating and drinking and death, and whether the patients had physical or psychological symptoms or other problems in the last 3 days before death. If the answer was yes, the physicians were asked to describe these symptoms or problems. Finally the physicians were asked whether it was their impressions that the final days went according to the patients' wishes; if not or partly, the physicians were asked to elaborate. We excluded patients who did not die and patients who were incompetent because of dementia, as they could not have deliberately decided to hasten death.

\section{Statistical Analysis}

Data were analyzed with IBM SPSS Statistics 20.0 (International Business Machines). Confidence intervals were calculated using the adjusted Wald method. Missing values were excluded from analysis and did not exceed $5 \%$, unless otherwise specified. To find predictors of time until death after starting VSED, we used Cox regression analysis (forward selection, with a cutoff of $P=.10$ ). Variables put into the model were age (categorized in 3 groups), ECOG performance status (3 categories: 0 to 2,3 , and 4 , for which higher status indicates greater disability) and diagnosis (3 categories: cancer, other severe physical diseases, no severe physical disease). Cases lasting more than 21 days were excluded from this analysis $(n=3)$ because we assumed that unknown factors prolonged survival (specifically, continued fluid intake).

Some family physicians described they were not informed and involved during VSED. We had concerns about whether these family physicians were a reliable source for information. As a result, we repeated the analysis on patients' motives separately for family physicians who were involved during VSED and informed in advance by the patient $(\mathrm{n}=37)$, and family physicians who were not $(\mathrm{n}=59)$. No significant differences were found (Fisher's exact test, $P>.05$ ). Also, no significant differences were found between family physicians involved during VSED ( $\mathrm{n}=53)$ and those not involved $(\mathrm{n}=43)$ for time until death (Cox regression analysis, $P=.67$ ) and each symptom before death (Fisher's exact test, $P>.05)$.

\section{RESULTS}

\section{Response}

Of the 1,100 randomly selected family physicians who received a questionnaire, 978 were eligible for the study.
Reasons for exclusion were: untraceable (70), no longer working as family physician (46), being on leave (3) and death (3). The response rate was $72.4 \%(n=708)$. Of the 270 physicians who did not complete the questionnaire, 121 sent in a response card stating the reasons for nonresponse. Main reason was lack of time $(n=88)$.

Of the 500 family physicians who received the additional questions regarding a VSED case, 440 were eligible, and 285 returned completed questionnaires (64.8\%). They reported on 103 cases. After 4 cases were excluded (1 patient changed her mind, and 3 patients had advanced dementia), there were 99 VSED cases for review.

Table 1 displays respondent characteristics of the 708 physicians. Family physicians with experience with VSED were somewhat older and had somewhat more work experience than family physicians without this experience.

\section{Prevalence and Opinions of VSED}

Table 1 shows that $46 \%$ of family physicians had experienced VSED (95\% CI, 42\%-49\%), 9\% in the last year (95\% CI, 7\%-11\%). Eighty-one percent found it conceivable to administer palliative sedation in VSED or had done so in the past (95\% CI, 78\%-84\%). One-third of family physicians had suggested VSED to a patient with a wish for PAS (34\%, 95\% CI, 30\%-37\%).

\section{Patient Characteristics}

Most patients (70\%) who hastened death by VSED were older (median age 83 years, range, 50 to 97 years), had severe disease (76\%), were dependent on others for everyday care (ECOG performance status $3-4,77 \%)$, and had a short life expectancy ( $74 \%$ less than a year) (Table 2).

\section{Decision to Hasten Death by VSED}

The most common motives for hastening death were somatic (79\%), existential (77\%), and related to dependence $(58 \%)$ (Table 3). In $19 \%$ of cases, the patient had requested PAS before starting $\mathrm{VSED}_{i}$ in $14 \%$ the request was denied, and in $4 \%$ there were other reasons for not performing PAS (such as objections from the patient's partner).

\section{Preparation and Terminal Phase}

Table 4 displays data for the period after the patients' decision to hasten death by VSED. In one-half of cases the family physicians were informed beforehand, and they were involved in $62 \%$. In $16 \%$ of cases neither the family physicians nor proxies were involved. In $28 \%$ of cases the family physicians administered palliative sedation. A minority of family physicians reported symptoms in the last 3 days of life $(36 \%)_{\text {; }}$ the most 
Table 1. Background Characteristics of Physician Respondents: Family Physicians With and Without VSED Experience

\begin{tabular}{|c|c|c|c|}
\hline Characteristic & $\begin{array}{c}\text { Total } \\
(\mathrm{N}=708)\end{array}$ & $\begin{array}{c}\text { Experience } \\
\text { With VSED } \\
(n=313)\end{array}$ & $\begin{array}{c}\text { No Experience } \\
\text { With VSED } \\
(n=383)\end{array}$ \\
\hline \multicolumn{4}{|l|}{ Age, y } \\
\hline Mean $(S D)^{a}$ & $50(8)$ & $52(8)$ & $49(9)$ \\
\hline Range & $31-72$ & $32-70$ & $31-72$ \\
\hline Sex, male, \% & 61 & 62 & 60 \\
\hline Is religious, \% ${ }^{\mathrm{b}}$ & 37 & 36 & 39 \\
\hline \multicolumn{4}{|l|}{ Working experience as family physician, y } \\
\hline Mean $(S D)^{a}$ & $19(9)$ & $20(9)$ & $18(9)$ \\
\hline Range & $1-42$ & $2-39$ & $1-42$ \\
\hline \multicolumn{4}{|l|}{ Additional expertise, \% } \\
\hline Received training in palliative care $^{c}$ & 73 & 75 & 72 \\
\hline Palliative care consultant & 2 & 2 & 3 \\
\hline \multicolumn{4}{|l|}{ Experiences with VSED, \% } \\
\hline Experience with VSED & 46 & 100 & NA \\
\hline Experience with VSED in the last year & 9 & 19 & NA \\
\hline \multicolumn{4}{|l|}{ Palliative sedation in VSED, \% } \\
\hline $\begin{array}{l}\text { Has administered palliative sedation } \\
\text { in case of VSED }\end{array}$ & 23 & 47 & NA \\
\hline $\begin{array}{l}\text { Conceivable to administer palliative } \\
\text { sedation in case of VSED }{ }^{\mathrm{a}, \mathrm{d}, \mathrm{e}}\end{array}$ & 81 & 90 & 73 \\
\hline \multicolumn{4}{|l|}{ PAS, $\%$} \\
\hline Has performed PAS & 79 & 82 & 77 \\
\hline Conceivable to perform PAS & 93 & 93 & 92 \\
\hline \multicolumn{4}{|l|}{ VSED and PAS, \% } \\
\hline $\begin{array}{l}\text { Has ever suggested VSED to a patient } \\
\text { with a wish for PASa }\end{array}$ & 34 & 49 & 21 \\
\hline \multicolumn{4}{|c|}{$\mathrm{NA}=$ not applicable; PAS = physician-assisted suicide; VSED = voluntary stopping of eating and drinking. } \\
\hline $\begin{array}{l}\text { a Significant difference between respondents } w \\
\text { ence, calculated by Fisher's exact test ( } 2 \text {-tailed) } \\
\text { tinuous variables. } P<.001 \text { in all cases. } \\
\text { b As described by respondent. Religion was Ch } \\
\text { ' Not including regular curricular training. } \\
\text { d Physicians who had done so were categorized } \\
\text { e Missing values for } 13.1 \% \text {. }\end{array}$ & $\begin{array}{l}\text { experience with } \\
\text { dichotomous va } \\
\text { anity in } 93 \% \text { of } \\
\text { der conceivable. }\end{array}$ & $\begin{array}{l}\text { SED and responde } \\
\text { ables and by inde } \\
\text { ases. }\end{array}$ & $\begin{array}{l}\text { is without this experi- } \\
\text { endent } t \text { test for con- }\end{array}$ \\
\hline
\end{tabular}

\section{DISCUSSION}

Almost one-half of Dutch family physicians had experience with VSED. Patients who hastened death by VSED were mostly older than 80 years and in poor health. The family physicians described their patients' last days of life as relatively comfortable.

\section{Choice for VSED}

In line with previous studies on death wishes, patients' motives to hasten death were both physical and psychosocial. ${ }^{4,5}$ In slightly more than one-half of cases, dependence on others played a direct role. Our study was conducted in the Netherlands, where physician-assisted suicide is allowed by law under strict conditions. Only 1 in 5 patients in our sample had requested PAS before their decision to hasten death by VSED. It seems that most patients who decided to hasten death by VSED consciously chose this method rather than PAS. VSED provided them with a prolonged and reversible dying phase instead of the abrupt death of PAS, giving them the opportunity for reflection, family interaction, and mourning. ${ }^{9,13,14}$ Also, they might not have wanted to

common symptom was pain (14\%). The median time until death was 7 days (Figure 1). In $8 \%$ of cases, dying was a prolonged process of more than 14 days.

\section{Predictors of a Prolonged Dying Phase}

We performed Cox regression analysis to test whether diagnosis, ECOG performance status, and age were predictors of time until death after starting VSED. The only significant predictor was an ECOG performance status of 3 (capable of limited self-care), compared with patients with an ECOG performance statue of 0 to 2 (capable of all self-care). These patients had a higher chance of dying at any time (hazard ratio $1.7,95 \%$ $\mathrm{CI}, 0.95-3.0, P=.077)$. The hazard ratio for patients with an ECOG performance status of 4 (completely disabled) compared with a performance status of 0 to 2 was not significant $(1.4,95 \% \mathrm{CI}, 0.78-2.68, P=.245)$. burden their physician ${ }^{11}$ or preferred not to rely on their physician to hasten their death. ${ }^{13,14}$ Patients who hastened death by VSED were generally older than patients requesting PAS (median age 84 years and 69 years, respectively) and had cancer less often $(27 \%$ and $80 \%$, respectively). ${ }^{28}$

\section{A Description of VSED}

In line with previous literature, family physicians were quite positive about VSED. ${ }^{9,14,17,23}$ It seems that VSED can be managed well in the home setting. This study is the first that gives an overview of symptoms encountered in VSED. Similar to the findings of Ganzini et al, almost all patients died within 2 weeks, ${ }^{23}$ but in some cases the dying process lasted a month or longer. In these cases, we assume that patients continued to ingest some fluids. ${ }^{11}$ 
Table 4. Characteristics of Preparation and Terminal Phases of VSED (96 Patients)

\begin{tabular}{|c|c|c|c|}
\hline Characteristic & $\%(95 \% \mathrm{Cl})$ & Characteristic & $\%(95 \% \mathrm{Cl})$ \\
\hline Preparation phase & & Terminal phase & \\
\hline \multicolumn{2}{|l|}{$\begin{array}{l}\text { Physician was informed of the patient's inten- } \\
\text { tion in advance }\end{array}$} & \multicolumn{2}{|l|}{ Symptoms in the last 3 days before death ${ }^{b}$} \\
\hline Yes, by the patient & $46(36-56)$ & Yes & $36(28-46)$ \\
\hline Yes, by the patient's proxy & $4(1-11)$ & $\begin{array}{l}\text { None } \\
\text { None (but palliative sedation was given) }\end{array}$ & $\begin{array}{l}42(32-52) \\
10(6-18)\end{array}$ \\
\hline $\begin{array}{l}\text { No, but the patient had stated that he/she } \\
\text { did not want to continue living }\end{array}$ & $25(17-35)$ & Don't know & $11(6-20)$ \\
\hline No & $25(17-35)$ & \multicolumn{2}{|l|}{ Symptoms reported ${ }^{c, d}$} \\
\hline Physician or proxy involvement & & Pain & $14(8-23)$ \\
\hline No family physician or proxy & $16(10-24)$ & Fatigue & $9(5-18)$ \\
\hline \multirow{2}{*}{\multicolumn{2}{|c|}{$\begin{array}{l}\text { Family physician (for guidance, support, or } \\
\text { care) }^{\mathrm{a}}\end{array}$}} & Impaired cognitive functioning & $8(4-16)$ \\
\hline & & Thirst or dry throate & $7(3-15)$ \\
\hline In preparing for VSED & $21(14-30)$ & Delirium & $6(2-13)$ \\
\hline During the process of VSED & $55(45-65)$ & Dyspnea & $6(2-13)$ \\
\hline Palliative sedation until death & $28(20-38)$ & Reduced consciousness & $5(1-12)$ \\
\hline No & $38(28-48)$ & Agitation & $5(1-12)$ \\
\hline Proxies $^{\mathrm{a}}$ & & Impaired communication & $4(1-10)$ \\
\hline In preparing for VSED & $44(34-54)$ & Other ${ }^{f}$ & $6(3-15)$ \\
\hline During the process of VSED & $53(43-63)$ & \multirow{2}{*}{\multicolumn{2}{|c|}{$\begin{array}{l}\text { Physicians' impression that dying process } \\
\text { went according to the patient's wish }\end{array}$}} \\
\hline No & $28(20-38)$ & & \\
\hline \multirow{9}{*}{ Don't know } & $3(1-9)$ & Yes & $80(71-87)$ \\
\hline & & Partly & $18(11-27)$ \\
\hline & & No & $2(0-8)$ \\
\hline & & \multicolumn{2}{|l|}{ If partly or no, reason whyc } \\
\hline & & Duration too long & $11(6-20)$ \\
\hline & & Patient preferred PAS & $3(1-9)$ \\
\hline & & Communication problems & $1(0-6)$ \\
\hline & & Inability to say goodbye & $1(0-6)$ \\
\hline & & Agitation & $1(0-6)$ \\
\hline
\end{tabular}

PAS = physician-assisted suicide; VSED = voluntary stopping of eating and drinking.

Note: Total number of cases was 96 , as data for 3 patients were missing (3.0\%).

${ }^{a}$ Respondents could give 1 or more answers.

b Phrasing of the question: "Did the patient have physical, psychological or other symptoms or complaints in the last 3 days before death?"

c Open-ended question; respondent could give multiple answers.

${ }^{d} \mathrm{n}=85,11$ did not know, 3 missing (13.9\%).

e Thirst 3\%, dry mouth or throat $3 \%$.

${ }^{f}$ Other: decubitus (2\%), (deterioration of) heart failure (2\%), gloom or sadness (2\%), edema (1\%), problems ingesting medication (1\%).

\section{Strengths and Weaknesses}

This study on VSED is the most comprehensive yet undertaken and is the first study on physicians' experience with VSED. The response rate was fairly high, and a relatively high number of cases was described.

One possible limitation is that we did not gather information from patients themselves, and we cannot report on cases about which the family physician was not aware. In the Netherlands, however, most people see their family physician regularly, and it seems unlikely for a patient to die by VSED without the family physician hearing about it. Second, this study was retrospective. The value of our data depends on the family physician's memory, and although caring for a dying patient is intense, and information is more likely to be retained, there is a risk for recall bias. Moreover, some family physicians might not have been fully informed of patients' symptoms, which would lead to underreporting. Symptoms reported, however, were not different for family physicians who were involved in VSED and those who were not. Third, cases of VSED in which the patient did not die were excluded, which might lead to underestimation of symptoms if patients with severe symptoms discontinued VSED. Fourth, this study included only those cases in primary care, whereas VSED is not confined to people residing at home, in a residential home, or in hospice care. ${ }^{35}$ Also, the patients described were mostly older and had a short life-expectancy, for whom forgoing food and fluids more rapidly leads to death. These results cannot therefore be extrapolated to younger, healthier people choosing VSED. 


\section{Figure 1. Cumulative survival curve for duration until death after start of VSED.}

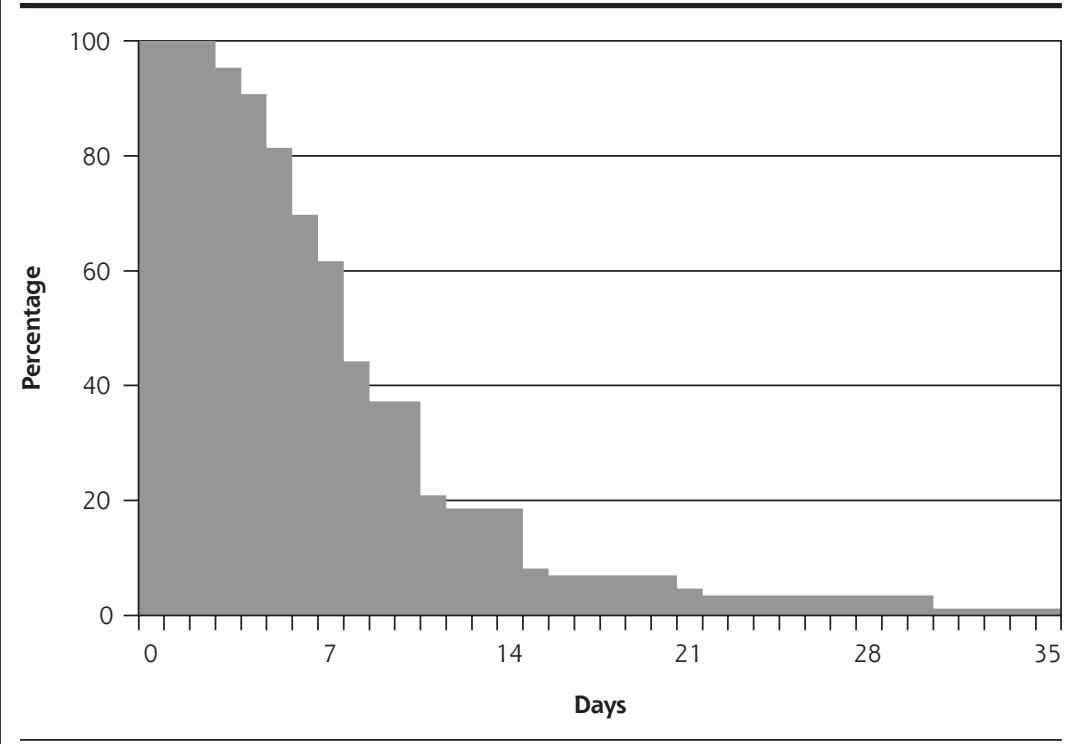

VSED $=$ voluntary stopping of eating and drinking.

Note: Median time to death was 7 days. Data for 86 patients; 10 responding physicians did not remember, and 3 missing (13.1\%)
To read or post commentaries in response to this article, see it online at http://www.annfammed.orgl content/13/5/421.

Key words: terminal care; palliative care; hospice care; withholding treatment; allowing to die; voluntary stopping of eating and drinking; death wish; hastening death

Submitted February 9, 2015; submitted, revised, May 14, 2015; accepted May 26, 2015.

Previous presentations: Presented in part as a poster presentation, GPs' Experiences With Patients Who Hasten Death by Voluntary Refusal of Food and Fluids, at the NAPCRG Annual meeting 2014, New York; and as a poster presentation, VRFF (Voluntary Refusal of Food and Fluid) as An Alternative to Euthanasia in Dutch GP Care, at the WONCA World Conference 2013, Prague.

Funding support: This study was funded by The Netherlands Organization for Research and Development (ZonMw).
Finally, we have no information about fluid intake, and when the patients started VSED is not clearly defined in our study. Chabot described many patients who stopped eating but continued to ingest (small amounts of) fluid until late in the process. ${ }^{11}$ In these cases, death can be delayed by weeks. For further research, we would advise to more precisely describe the amount of food and fluid ingested.

\section{Practice Implications}

VSED is not uncommon in Dutch primary care, and it could be a relatively comfortable way to hasten death if sufficient palliative care is available. Our findings give family physicians some insight into what to expect if a patient decides to hasten death by VSED. Family physicians can play an important role in counseling the patient and their proxies and in providing palliative care. Attention should be given to mouth care and to the management of pain and delirium or agitation. Evidence-based clinical guidelines could help physicians providing palliative care.

We recommend further research to substantiate our findings. Prospective studies are needed on prevalence and treatment of complications and predictors of a complicated or prolonged dying process. If possible, these studies should gather data from patients or proxies and include younger and healthier persons. Furthermore, qualitative research could increase our understanding of patients' motives to hasten death by VSED.

\section{References}

1. Kehl KA. Moving toward peace: an analysis of the concept of a good death. Am J Hosp Palliat Care. 2006;23(4):277-286.

2. McNamara B. Good enough death: autonomy and choice in Australian palliative care. Soc Sci Med. 2004;58(5):929-938.

3. Pool R. "You're not going to dehydrate mom, are you?": Euthanasia, versterving, and good death in the Netherlands. Soc Sci Med. 2004;58(5):955-966.

4. Hudson PL, Kristjanson LJ, Ashby M, et al. Desire for hastened death in patients with advanced disease and the evidence base of clinical guidelines: a systematic review. Palliat Med. 2006;20(7):693-701.

5. Monforte-Royo C, Villavicencio-Chávez C, Tomás-Sábado J, Mahtani-Chugani V, Balaguer A. What lies behind the wish to hasten death? A systematic review and meta-ethnography from the perspective of patients. PLoS One. 2012;7(5):e37117.

6. Hales S, Zimmermann C, Rodin G. The quality of dying and death. Arch Intern Med. 2008;168(9):912-918.

7. Ashby M. The dying human: a perspective from palliative medicine. In: Kellehear A, ed. The Study of Dying. 1st ed. Cambridge, England: Cambridge University Press; 2009:76-98.

8. Savulescu J. A simple solution to the puzzles of end of life? Voluntary palliated starvation. J Med Ethics. 2014;40(2):110-113.

9. Bernat JL, Gert B, Mogielnicki RP. Patient refusal of hydration and nutrition. An alternative to physician-assisted suicide or voluntary active euthanasia. Arch Intern Med. 1993;153(24):2723-2728.

10. Quill TE, Lo B, Brock DW. Palliative options of last resort: a comparison of voluntarily stopping eating and drinking, terminal sedation, physician-assisted suicide, and voluntary active euthanasia. JAMA. 1997;278(23):2099-2104.

11. Chabot BE. Auto-euthanasie [Auto-euthanasia]. 2nd ed. Amsterdam, the Netherlands: Bert Bakker; 2007. 
12. Ivanović N, Büche D, Fringer A. Voluntary stopping of eating and drinking at the end of life - a 'systematic search and review' giving insight into an option of hastening death in capacitated adults at the end of life. BMC Palliat Care. 2014;13(1):1.

13. Vink T. Choice of ways towards death: life termination and maintaining control [Dutch]. Tijdschrift voor Humanistiek. 2010;11:105-115.

14. Schwarz J. Exploring the option of voluntarily stopping eating and drinking within the context of a suffering patient's request for a hastened death. J Palliat Med. 2007;10(6):1288-1297.

15. Quill TE, Byock IR; ACP-ASIM End-of-Life Care Consensus Panel. Responding to intractable terminal suffering: the role of terminal sedation and voluntary refusal of food and fluids. Ann Intern Med. 2000;132(5):408-414. Erratum in Ann Intern Med. 2000;132(12):1011.

16. Rady MY, Verheijde JL. Distress from voluntary refusal of food and fluids to hasten death: what is the role of continuous deep sedation? J Med Ethics. 2012;38(8):510-512.

17. Berry ZS. Responding to suffering: providing options and respecting choice. J Pain Symptom Manage. 2009;38(5):797-800.

18. Jansen LA. No safe harbor: the principle of complicity and the practice of voluntary stopping of eating and drinking. J Med Philos. 2004;29(1):61-74.

19. Royal Dutch Medical Assosciation (KNMG). KNMG Position Paper: The Role of the Physician in the Voluntary Termination of Life. Utrecht, the Netherlands:Royal Dutch Medical Assosciation; 2011.

20. Schwarz JK. Stopping eating and drinking. Am J Nurs. 2009;109(9): 52-61.

21. Onwuteaka-Philipsen BD, Brinkman-Stoppelenburg A, Penning C, de Jong-Krul GJF, van Delden JJM, van der Heide A. Trends in end-oflife practices before and after the enactment of the euthanasia law in the Netherlands from 1990 to 2010: a repeated cross-sectional survey. Lancet. 2012;380(9845):908-915.

22. Chabot BE, Goedhart A. A survey of self-directed dying attended by proxies in the Dutch population. Soc Sci Med. 2009;68(10):1745-1751

23. Ganzini L, Goy ER, Miller LL, Harvath TA, Jackson A, Delorit MA. Nurses' experiences with hospice patients who refuse food and fluids to hasten death. N Engl J Med. 2003;349(4):359-365.

24. Koopmans RTCM, Dekkers WJM. Refusal of food and fluids of a psychiatric patient in order to hasten death: obstacles for patient, family and care-team [Dutch]. Tijdschr Gerontol Geriatr. 2012;43(2):98-102.
25. Bohn Stafleu-van Loghum medical databank [in Dutch]. http://www. bsl.nl/adresverhuur. Accessed Oct 5, 2011.

26. The Hague, the Netherlands: Central Committee on Research Involving Human Subjects. http://www.ccmo.nl/en. Accessed May 1, 2015.

27. Oken MM, Creech RH, Tormey DC, et al. Toxicity and response criteria of the Eastern Cooperative Oncology Group. Am J Clin Oncol. 1982;5(6):649-655.

28. Brinkman-Stoppelenburg A, Vergouwe $Y$, van der Heide $A$, Onwuteaka-Philipsen BD. Obligatory consultation of an independent physician on euthanasia requests in the Netherlands: what influences the SCEN physicians judgment of the legal requirements of due care? Health Policy. 2014;115(1):75-81.

29. Onwuteaka-Philipsen BD, Rurup ML, Pasman HR, van der Heide A. The last phase of life: who requests and who receives euthanasia or physician-assisted suicide? Med Care. 2010;48(7):596-603.

30. KNMG Royal Dutch Medical Association, VEVN Dutch Nurses' Association. KNMG Position Paper: Caring for People Who Consciously Choose Not to Eat and Drink So as to Hasten the End of Life. Utrecht, the Netherlands:Royal Dutch Medical Assosciation; 2014.

31. Breitbart W, Chochinov HM, Passik SD. Psychiatric symptoms in palliative medicine. In: Hanks G, Cherny NI, Christakis NA, Fallon M, Kaasa S, Portenoy RK, eds. Oxford Textbook of Palliative Medicine. $4^{\text {th }}$ ed. Oxford, England: Oxford University Press; 2010:1453-82.

32. World Health Organisation. WHO's pain relief ladder. http://www. who.int/cancer/palliative/painladder/en/\#. Accessed Feb 2, 2015.

33. Terman SA. The Best Way to Say Goodbye: A Legal Peaceful Choice at the End of Life. 1st ed. Carlsbad, California: Life Transitions Publications; 2007.

34. McCann RM, Hall WJ, Groth-Juncker A. Comfort care for terminally ill patients. The appropriate use of nutrition and hydration. JAMA. 1994;272(16):1263-1266.

35. Koopmans RT, Sindram IP, Dekkers WJ. Conscious refusal of food and fluids by Dutch nursing home patients in order to hasten death: a matter regarding patient and physician? [Dutch]. Ned Tijdschr Geneeskd. 2004;148(11):536-539. 